\title{
A study of empathy decline in students from five health disciplines during their first year of training
}

Paula Nunes $^{1}$, Stella Williams ${ }^{1}$, Bidyadhar Sa ${ }^{1}$, Keith Stevenson ${ }^{2}$

\author{
${ }^{1}$ Faculty of Medical Sciences, University of the West Indies, Trinidad and Tobago \\ ${ }^{2}$ School of Health, Glasgow Caledonian University, UK
}

Correspondence: Paula Nunes, Unit of Public Health and Primary Care, Faculty of Medical Sciences, University of the West Indies, Trinidad and Tobago. Email: paula.nunes@sta.uwi.edu

\begin{abstract}
Objectives: This cross-sectional study examines the selfreported empathy levels of undergraduate students in five different health sciences disciplines before and after one year of training at the St Augustine Campus, University of the West Indies.

Methods: Students enrolled into the schools of dentistry, pharmacy, medicine, veterinary medicine and nursing self administered the Jefferson Scale of Empathy on entering their first year of training $(n=355)$. Mean empathy scores were then compared between and among groups to scores on retesting at the end $(n=366)$ of their first year using independent $\mathrm{t}$ - tests and one way between groups using ANOVA with planned comparisons.

Results: Female students and students older than 27 years were found to be more empathic than male students and those less than 21 years respectively. The highest mean empathy scores on entry to university were noted in nursing
\end{abstract}

and dental students. On repeat testing mean empathy scores declined in all 5 groups, with the declines among medical, nursing and dental students achieving statistical significance.

Conclusions: This study shows that the decline in self reported empathy scores starts during the first year of training. Whilst this decline may be partly due to a 'settling in' phenomenon with a change from idealism to realism, students may also be displaying an adaptive response to new responsibilities and an increasing workload. With the current trend of blurred professional boundaries for healthcare providers, empathy is an important skill to be developed by all disciplines. Health educators now need to consider addressing those factors that may check its further decline.

Keywords: Empathy, medical education, nursing, dental, undergraduate

\section{Introduction}

Empathy is a much talked about concept, yet is one of the least understood aspects of health care. It has been described as having two components- cognitive and affective: the physician recognizes and understands the patient's perspective and is then able to reflect this back to the patient. $^{1}$

The Association of American Medical Colleges (AAMC) ${ }^{2}$ has defined 'empathy' as "considering oneself as the opposite person" and posits the development of empathy as important for improved patient-physician relations. Empathy has also been mandated by the AAMC as one of the Learning Objectives for Medical School Education: "physi- cians must be compassionate and empathetic in caring for their patients." ${ }^{2}$ The development of empathy during training must therefore play a critical role in the training of medical students as it affects their overall ability to communicate with patients and clients.

In addition to the enhancement of the physician patient relationship, ${ }^{3}$ higher levels of empathy are associated with more accurate diagnoses, increased patient engagement in their health care and better adherence to therapy. ${ }^{4}$ Although there have been many studies on the clinical impact of empathy, particularly in physicians, medical students and nurses, ${ }^{5}$ empathy has been less studied among other health 
professionals. ${ }^{6,7}$ Yet, empathy is considered to be equally important to successful and meaningful patient encounters for dentists, ${ }^{8}$ pharmacists ${ }^{6}$ and veterinarians. ${ }^{9,10}$

Hojat and colleagues and Chen and colleagues reported that measured empathy in medical students decline in the third year of training and Sherman and Cramer in their review of empathy in dental students found a similar decrease in the second year of dental training., ${ }^{8,11,12,13}$ Increasing workload, time pressures, competitiveness, technology-driven therapeutics and increased cynicism about the caring process are all believed to contribute to the decline in empathy. ${ }^{12}$ Similar findings have been presented by UK researchers. ${ }^{14}$

In his recent paper, Michalec ${ }^{15}$ studied the effect of stressors on medical students in the USA during Years 1 to 3. He proposed that empathic decline may be an adaptive response to stressors in their learning environment. He posits that students with high empathy scores adapt to stress by 'shedding' empathic tendencies in an effort to reduce their vulnerability.

Research has shown that patients and clients place greater value on the health provider who has an empathic disposition. With the current trend of changing skill mix and blurring of professional boundaries for healthcare providers, ${ }^{16,17}$ empathy is therefore one of the core competencies essential to all health disciplines.

At the Faculty of Medical Sciences of the University of the West Indies where this study was conducted, six disciplines comprising dental, nursing, pharmacy, physicians, speech therapists and veterinarian students are tutored in communication skills in discipline-specific classes by the same tutors. We know from previous studies that students enter with high empathy scores, we also know of the decline in the third year in medical students and dentists but no study has looked at what happens to empathy levels of these and other health professionals during the first year of training. ${ }^{6,7,8,12}$ We feel that this assessment may help us to not only understand the changing trend but also help us to consider how we might create learning activities that would help stem any decline. Our objective in this study was to measure empathy scores of five groups of health sciences students at the beginning and the end of their first year of training and to review any changes that occur with respect to age, gender and health discipline.

\section{Methods}

\section{Instrument and Scoring}

The Jefferson Scale of Empathy (JSE), ${ }^{18}$ a 20 item self reporting questionnaire was administered to the first year student population. This scale was developed by researchers at the Center for Research in Medical Education and Health Care at Jefferson Medical College to measure empathy in physicians and health care providers. The version applied (S-version) was previously adapted for use by medical and other health profession students, to take into account their attitude to the patient - doctor relationship. The 20 item test uses a 7 point Likert scale for each item ( $1=$ strongly disagree and $7=$ strongly agree). Respondents with high scores are interpreted as having more empathic behavioural orientation than those respondents with lower scores.

\section{Sample}

All 437 first year students enrolled into the 6 health science disciplines in the 2009-2010 cohort were invited to complete the JSE-S- version scale at the beginning (T1) and at the end of their first year of training (T2). Since the students enrolled in the speech and language discipline accounted for less than $2 \%$ of the study population this discipline was not included in the comparison and the cross-sectional study examined students in the 5 health disciplines: pharmacy, dentistry, veterinary medicine, nursing and medicine. A total of 355 (81\%) students completed the questionnaire at the beginning of year 1 and 366 (84\%) students completed the questionnaire at the end of year 1 . The demographic distribution of the sample population is reported in Table 1.

Table 1. Demographic distribution of health sciences students in Class $2009-2010(\mathrm{~N}=355$ at $\mathrm{T} 1, \mathrm{~N}=366$ at $\mathrm{T} 2)$

\begin{tabular}{llcc}
\hline & & $\begin{array}{c}\text { Beginning of Year (T1) } \\
\text { N (\%) }\end{array}$ & $\begin{array}{c}\text { End of Year (T2) } \\
\text { N (\%) }\end{array}$ \\
\hline Gender & Male & $96(27)$ & $102(28)$ \\
& Female & $259(73)$ & $264(72)$ \\
Age (years) & $<21$ & $252(71)$ & $245(67)$ \\
& $22-27$ & $59(17)$ & $77(21)$ \\
& $>27$ & $44(12)$ & $44(12)$ \\
Program & Pharmacy & $102(29)$ & $104(28)$ \\
& Dental & $24(7)$ & $25(7)$ \\
& Veterinary & $36(10)$ & $37(10)$ \\
& Nursing & $31(9)$ & $38(10)$ \\
& Medical & $162(45)$ & $162(44)$ \\
\hline Total (N) & & 355 & 366 \\
\hline
\end{tabular}

\section{Data Collection}

Ethical approval for the study was granted by University of West Indies, St Augustine Campus, Research Ethics Board. The questionnaires were then administered during the students' orientation week (T1) and scored according to the instruction manual for the questionnaire. The results (T1) were retained and compared with the results of the second testing (T2) carried out 9 months later at the end of their first year's taught programme.

\section{Data Analysis}

As the questionnaires were answered anonymously by the students they could not be matched at testing time T1 and T2 and the two samples from each health sciences discipline were therefore treated as independent samples. Empathy mean scores, standard deviations and standard error of the mean was calculated for the five (5) different health disci- 
plines at T1 and T2 of the first academic year (Table 2). Empathy mean scores (dependent variable) were subjected to large independent-samples t-tests using SPSS Version 16 to explore whether significant differences existed between groups because of gender and the time of testing.

Table 2. Comparison of empathic mean scores for health sciences students at $\mathrm{T} 1(\mathrm{~N}=355)$ and $\mathrm{T} 2(\mathrm{~N}=366)$ in Class 20092010

\begin{tabular}{llcccc}
\hline Gender & Testing Time & Mean & $\mathrm{N}$ & SD & SEM $^{*}$ \\
\hline Male & Beginning of Year (T1) & 106.22 & 96 & 13.469 & 1.375 \\
& End of Year (T2) & 104.57 & 102 & 15.062 & 1.491 \\
& Total & 105.37 & 198 & 14.300 & 1.016 \\
Female & Beginning of Year (T1) & 112.51 & 259 & 12.644 & 0.786 \\
& End of Year (T2) & 108.30 & 264 & 13.074 & 0.805 \\
& Total & 110.39 & 523 & 13.022 & 0.569 \\
Group & Beginning of Year (T1) & 110.81 & 355 & 13.155 & 0.698 \\
& End of Year (T2) & 107.26 & 366 & 13.739 & 0.718 \\
& Total & 109.01 & 721 & 13.562 & 0.505 \\
\hline
\end{tabular}

* Standard Error of the Mean

To compare the impact of age on empathy a one-way between-groups analysis of variance (ANOVA) with post hoc comparisons using the Scheffe's test was performed (independent -groups design). Students were divided into three groups in relation to age; group $1=$ less than 21 years; group $2=22$ to 27 years and group $3=$ more than 27 years.

To examine for differences between and among the various health disciplines at $\mathrm{T} 1$ and $\mathrm{T} 2$, planned orthogonal comparisons were performed using a contrast approach and a $5 \mathrm{X} 2$ completely crossed factorial design (CRD) in the one way ANOVA.

\section{Results}

All questionnaires were appropriately answered according to the JSE manual. The original Alpha reliability estimate for JSE (S) was 0.80 . The Cronbach Alpha reliability estimates obtained in both testing at T1 and T2 were 0.784 and 0.773 respectively.

Comparison of mean empathy scores by gender revealed that the empathy scores for females (mean=112.51, $\mathrm{SD}=12.64)$ were significantly higher than for males (mean=105.37, $\mathrm{SD}=14.3$ ) at $\mathrm{t}=-4.494$, and $\mathrm{p}<0.01$ ).

The one way between-groups ANOVA and post hoc comparisons using the Scheffe's test was conducted to compare differences in empathy scores between students because of age. The analyses revealed significant differences in empathy scores between groups at $\mathrm{T} 1\left[\mathrm{~F}_{(2,352)}=5.146\right.$, $\mathrm{p}=0.006$ ] but no significance at T2. Post hoc multiple comparisons using the Scheffe's test to examine differences between groups 1 to 3 at $\mathrm{T} 1$ indicated that the mean empathy score for group 1 (mean=109.73, $\mathrm{SD}=13.55)$ was significantly different from group 3 (mean=116.52, $\mathrm{SD}=11.346)$ at $\mathrm{p}<0.05$ ) (Table 3). Of all the health disciplines, nursing students had the highest mean empathy scores at T1 (mean=116.65, SD=10.78) and T2 (mean=109.21, SD=13.0). Comparison of mean empathy scores at $\mathrm{T} 1$ (mean $=110.81$, $\mathrm{SD}=13.115)$ and $\mathrm{T} 2$ (mean=107.26, SD 13.739: $\mathrm{t}=3.541$, $\mathrm{p}<0.01)$ for the first year students using the independentsamples t-test showed a significant decline in the mean empathy scores. This is demonstrated graphically in Figure 1. Planned comparisons employing orthogonal contrasts revealed that there was a statistical difference in empathy scores among dental, nursing and medical students between testing T1 and T2. This is reported in Table $4 . \mathrm{F}_{(2,711)}=10.66$, $\mathrm{p}=0.001 ; \mathrm{F}_{(4,711)}=5.52, \mathrm{p}=0.02 ;$ and $\mathrm{F}_{(5,711)}=6.31, \mathrm{p}=0.01$ respectively. The $\mathrm{F}$ test for the one way ANOVA between groups for the different health disciplines at $\mathrm{T} 1$ and at $\mathrm{T} 2$ was not significant so post hoc multiple comparisons were not performed.

Table 3. Post hoc analyses of empathic scores (Scheffe's test) according to age $(\mathrm{N}=355)$

\begin{tabular}{|c|c|c|c|c|c|c|}
\hline \multirow[t]{2}{*}{ (I) Age } & \multirow[t]{2}{*}{ (J) Age } & \multirow{2}{*}{$\begin{array}{c}\text { Mean } \\
\text { Difference } \\
(I-J)\end{array}$} & \multirow[t]{2}{*}{ SEM } & \multirow[t]{2}{*}{$\mathrm{p}$-value } & \multicolumn{2}{|c|}{$\begin{array}{l}95 \% \text { Confidence } \\
\text { Interval }\end{array}$} \\
\hline & & & & & $\begin{array}{l}\text { Lower } \\
\text { Bound }\end{array}$ & $\begin{array}{l}\text { Upper } \\
\text { Bound }\end{array}$ \\
\hline \multirow[t]{2}{*}{$<21$} & $22-27$ & -1.460 & 1.8811 & 0.740 & -6.08 & 3.16 \\
\hline & $27+$ & $-6.797^{*}$ & 2.125 & 0.006 & -12.02 & -1.57 \\
\hline \multirow[t]{2}{*}{$22-27$} & $<21$ & 1.460 & 1.8811 & 0.740 & -3.16 & 6.08 \\
\hline & $27+$ & -5.336 & 2.590 & 0.121 & -11.70 & 1.03 \\
\hline \multirow[t]{2}{*}{$27+$} & $<21$ & $6.797^{*}$ & 2.125 & 0.006 & 1.57 & 12.02 \\
\hline & $22-27$ & 5.336 & 2.590 & 0.121 & -1.03 & 11.70 \\
\hline
\end{tabular}

* The mean difference is significant at the 0.05 level.

Sub-analysis of the items on the JSE revealed that on entry two items produced ambivalent empathy scores that were in the majority $=4$ (not sure) on the 7 point Likert scale. Item 3'It is difficult for me to view things from my patient's perspective' (mean $=(4.78)$ and Item 6. 'Because people are different, It is difficult for me to see things from my patient's perspective' (mean=4.36). On completion of year one the students again showed ambivalence on these two items; Item $3($ mean $=4.39)$ and Item 6 ( $($ mean=3.89).

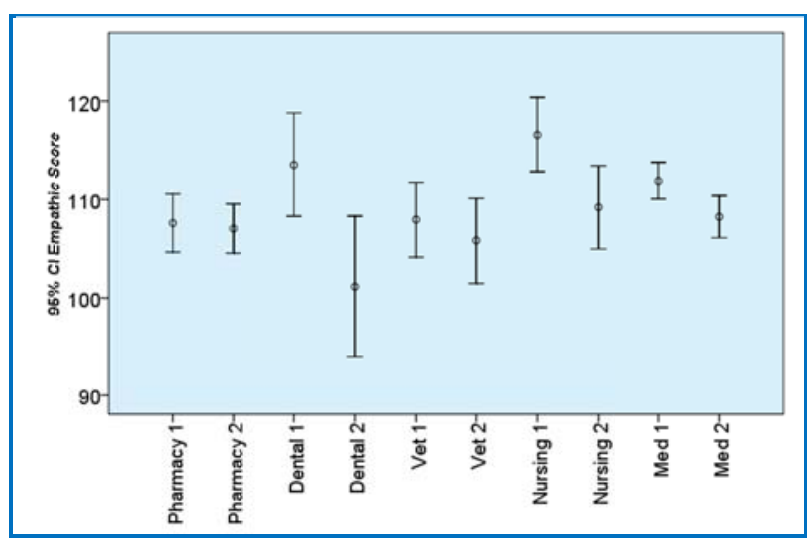

Figure1. Changes in mean empathy scores with time across health disciplines in class 2009-2010 ( $N=355$ at $\mathrm{T} 1, \mathrm{~N}=366$ at T2)

\section{Discussion}

Empathy, a much studied concept, is an attribute that is 
valued by patients ${ }^{19}$ and medical educators. ${ }^{2}$ However, a decline in empathy has been described by Hojat and colleague ${ }^{20}$ in medical students, nurses and dental students on their exposure to clinical setting. This study explored empathy in students enrolled in five different health disciplines; pharmacy, dentistry, veterinary medicine, nursing and medicine.

Table 4. The one way between -groups ANOVA with planned orthogonal comparisons ( $\mathrm{N}=355$ at $\mathrm{T} 1 ; \mathrm{N}=366$ at T2)

\begin{tabular}{|c|c|c|c|c|c|c|c|c|c|c|}
\hline \multicolumn{11}{|c|}{ Contrast Coefficients ( Group within time) } \\
\hline $\begin{array}{l}\text { Con- } \\
\text { trast }\end{array}$ & $\begin{array}{l}- \\
\text { বे } \\
\tilde{\sigma} \\
\sum_{0}^{0} \\
\frac{\pi}{\alpha}\end{array}$ & 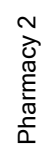 & 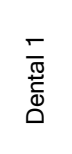 & $\begin{array}{l}\frac{N}{\overline{0}} \\
\frac{\pi}{\tilde{L}} \\
\text { D. }\end{array}$ & 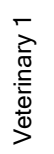 & 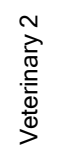 & 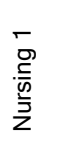 & 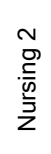 & $\begin{array}{l}\overline{\overline{0}} \\
\frac{\overline{0}}{\overline{0}} \\
\frac{0}{\Sigma}\end{array}$ & $\begin{array}{l}\frac{N}{\pi} \\
\frac{0}{\overline{7}} \\
\frac{0}{\Sigma}\end{array}$ \\
\hline 1 & 1 & -1 & 0 & 0 & 0 & 0 & 0 & 0 & 0 & 0 \\
\hline 2 & 0 & 0 & 1 & -1 & 0 & 0 & 0 & 0 & 0 & 0 \\
\hline 3 & 0 & 0 & 0 & 0 & 1 & -1 & 0 & 0 & 0 & 0 \\
\hline 4 & 0 & 0 & 0 & 0 & 0 & 0 & 1 & -1 & 0 & 0 \\
\hline 5 & 0 & 0 & 0 & 0 & 0 & 0 & 0 & 0 & 1 & -1 \\
\hline \multicolumn{11}{|c|}{ Contrast Tests of Empathy Score } \\
\hline \multicolumn{2}{|c|}{ Contrast } & \multicolumn{3}{|c|}{$\begin{array}{l}\text { Value of } \\
\text { Contrast }\end{array}$} & \multicolumn{2}{|c|}{ SEM } & \multicolumn{2}{|c|}{$\mathrm{t}$} & \multicolumn{2}{|c|}{$\mathrm{p}$-value } \\
\hline \multicolumn{2}{|c|}{1} & \multicolumn{3}{|c|}{0.57} & \multicolumn{2}{|c|}{1.855} & \multicolumn{2}{|c|}{0.307} & \multicolumn{2}{|c|}{0.759} \\
\hline \multicolumn{2}{|c|}{2} & \multicolumn{3}{|c|}{12.42} & \multicolumn{2}{|c|}{3.805} & \multicolumn{2}{|c|}{3.265} & \multicolumn{2}{|c|}{0.001} \\
\hline \multicolumn{2}{|c|}{3} & \multicolumn{3}{|c|}{2.13} & \multicolumn{2}{|c|}{3.117} & \multicolumn{2}{|c|}{0.685} & \multicolumn{2}{|c|}{0.494} \\
\hline \multicolumn{2}{|c|}{4} & \multicolumn{3}{|c|}{7.43} & \multicolumn{2}{|c|}{3.222} & \multicolumn{2}{|c|}{2.307} & \multicolumn{2}{|c|}{0.021} \\
\hline \multicolumn{2}{|c|}{5} & \multicolumn{3}{|c|}{3.72} & \multicolumn{2}{|c|}{1.479} & \multicolumn{2}{|c|}{2.512} & \multicolumn{2}{|c|}{0.012} \\
\hline
\end{tabular}

The mean empathy scores obtained in our study were generally lower than those reported in the literature. This variation is probably attributable to the socio-cultural differences in communicative styles of peoples of the Caribbean. Nevertheless, females were found to have significantly higher empathy scores than males and this finding is consistent with international studies, ${ }^{6,8,12}$ where this dissimilarity is thought to be due to factors such as differences in socialisation, ${ }^{21}$ a gender-genetic difference, ${ }^{22}$ or a preference of females to self report empathic behaviour. ${ }^{23}$ Females far outnumbered males in our study population and this parallels the trend of increasing numbers of females pursuing tertiary education in the Caribbean and internationally.

Concerning age, we found that students who were more than 27 years old (group 3) had higher empathy score than those who were less than 21 years (group 1). Whereas this difference was statistically significant at $\mathrm{T} 1$, it was not significant at T2. There is a lack of consistent published data on the relationship between empathy and age in persons up to the age of $50 .{ }^{24}$ We suggest that older students (group 3) felt more able to identify with the patient's perspective because of additional life experiences.

A decline in the mean empathy scores was observed among all health disciplines after completion of the first academic year. While nursing and dental students started with the highest empathy scores we noted a significant decline in their scores in addition to that seen with medical students. One can argue that the high empathy scores in the nurses may in part be due to their age (more than 27 years old) and gender (female). However previous studies comparing nursing students to their medical counterparts report higher measured empathy scores. ${ }^{24}$ Similarly, Sherman and Cramer ${ }^{8}$ in their cross sectional survey of dental students commented that the scores obtained by dental students were comparable to those of psychiatry residents.

Crandal ${ }^{26}$ has suggested that individuals with stronger empathic dispositions appear to be more resistant to erosion in empathy and Yaravistsch and colleagues. ${ }^{27}$ and Cinar and colleagues. ${ }^{28}$ found that despite the fall in empathy on patient exposure, both dental and nursing students seem to eventually recover. These findings however do not call for complacency and researchers now need to address what this decrease in empathy in the preclinical years represents and whether it calls for positive action from educators to address it.

Pharmacy $^{6}$ and veterinary students ${ }^{9}$ were found on the other hand to have the lowest empathy scores on entering the first year of training, with little change in their empathy scores on completion of the first year. This suggests that the factors that affect the empathy decline in nursing, dental and medical students may not be applicable to these two groups. Nonetheless, pharmacists are increasingly called upon to provide counseling to patients in addition to dispensing medication. In addition patients often seek the advice of their local pharmacist before attending a physician. This finding therefore provides evidence to support the premise that training in empathy is also important for pharmacy students.

We would like to suggest that the decline in empathy scores during the first year of training is in part due to a 'settling in' effect. Whereas the students on entry are eager to show that they have the positive attributes of a compassionate health care provider, their idealism is less evident as the year progresses. Furthermore, students lose sight of their primary goal to care for patients and idealism gives way to the realization that to complete this stage of training successfully they need to learn large volumes of information. Learning priorities are mainly determined by high stakes, fact based examinations and options such as communication skills development and the need to display empathy are therefore sidelined.

Recently Bonvicini and colleagues ${ }^{29}$ studied communication skills training to determine if this could counteract the decline in empathy. Their results strongly supported the hypothesis that training in empathic behavior made a significant difference in physician empathic expression during patient interactions. The study we have conducted highlights that if empathy levels are dropping as early as the first year of training there is an argument for introducing training in empathic skills for all health sciences students at the beginning of, and throughout, their training. Michalec ${ }^{15}$ 
in his recent study of preclinical students postulated that medical students 'shed' empathy as an adaptive response to school specific stressors such as workload, financial constraints and perceived mistreatment, as the possible cause of the pervasive decline in empathy scores. Newton and colleagues ${ }^{30}$ also commented on the increase in cynicism of students as they advance through their clinical years.

We suggest that organizational changes should be introduced that encourage supporting students academically and emotionally as they progress through their training. Moreover changes in curriculum design should ensure maintenance and development of empathy in students. These may include interprofessional learning, development of a team work ethic, changes in assessment process and a change in emphasis from fact based learning to applied learning. ${ }^{6,31}$

\section{Limitations of Study}

This study looked at empathy scores from students in 5 health disciplines on entry and on completion of their first year of training. The sensitive nature of the study protocol required that the students be given complete anonymity; therefore the data we gathered was treated as if the two groups were independent groups at $\mathrm{T} 1$ and $\mathrm{T} 2$. We recognize that a repeated measures design would have been more logical however the size of the student sample at both testing times was large enough for us to have confidence in the results. The reported general decline in empathy during the first year of training of the five groups of health sciences students needs to be explored further. It may be that the concept of empathy in health sciences students needs to be examined in more detail to establish exactly what is changing when empathy scores of students begin to decline.

\section{Conclusions}

The study reported here found that there was a general decline in empathy across all five groups of health sciences students over their first year of training. The authors suggest that medical educators take note of the likely decline in empathy in their students as early as the first year and adopt communication teaching strategies to promote the development of empathy and reduce its potential further decline. Further longitudinal research into the effect of communication training in improving medical student empathic behavior should be encouraged.

\section{References}

1. Hojat M, Mangione S, Nasca TJ, Cohen MJM, Gonnella JS, Erdmann JB, et al. The Jefferson scale of physician empathy: development and preliminary psychometric data. Educ Psychol Meas. 2001;61:349-65.

2. Anderson M, Cohen J, Hallock J, Kassebaum D, Turnbull J, Whitcomb M. Report I learning objectives for medical student education: guidelines for medical schools Washington: Association of American Medical Colleges; 1998; Available from: https://services.aamc.org/publications /showfile.cfm?file=version87.pdf\&prd_id=198\&prv_id=239 \&pdf_id=87.

3. Matthews D, Suchman A, Branch W. Making "connexions": Enhancing the therapeutic potential of patientclinician relationships. Ann Intern Med. 1993;118:973-7.

4. Halpern J. From detached concern to empathy: humanizing medical practice. New York: Oxford University Press; 2001.

5. Yu J, Kirk M. Measurement of empathy in nursing research: systematic review. J Adv Nurs. 2008;64:440-54.

6. Chen J, LaLopa J, Dang D. Impact of patient empathy modeling on pharmacy students caring for the underserved. Am J Pharm Educ. 2008;72:40.

7. Fields S, Hojat M, Gonella J, Nasca T, Veloski J, Kane G. Comparisons of nurses and physicians on an operational measure of empathy. Eval Health Prof. 2004;2780-94.

8. Sherman J, Cramer A. A measurement of changes in empathy during dental school. J Dent Educ. 2005;69:338345.

9. Mills J, Baguley J, Coleman G, Meehan M. Enhancing communication and life skills in veterinary students: curriculum development and assessment of methods. Sydney: Australian Learning and Teaching Council Ltd; 2009.

10. Halpern J. What is clinical empathy? J. Gen Intern Med. 2003;18:670-674.

11. Hojat M, Mangione S, Nasca T, Rattner S, Erdmann J, Gonnella J, et al. An empirical study of decline in empathy in medical school. Med Educ. 2004;38:934-41.

12. Hojat M, Vergare MJ, Maxwell K, Brainard G, Herrine SK, Isenberg GA, Veloski J, Gonnella JS. The devil is in the third year: a longitudinal study of erosion of empathy in medical school. Acad Med. 2009;84:1182-91.

13. Chen D, Lew R, Hershman W, Orlander J. A crosssectional measurement of medical student empathy. J Gen Intern Med. 2007;22:1434-8.

14. Masson N, Lester $\mathrm{H}$. The attitudes of medical students towards homeless people: does medical school make a difference? Med Educ. 2003;37:869-72.

15. Michalec B. An assessment of medical school stressors on preclinical students' levels of clinical empathy. Current Psychology. 2010;29:210-21.

16. Kennedy JG. Over the counter drugs. BMJ. 1996; 312:593-4.

17. Williams A, Sibbald B. Changing roles and identities in primary health care: exploring a culture of uncertainty. J Adv Nurs. 1999;29:737-45.

18. Hojat M. User's guide: the Jefferson scale of physician empathy. Philadelphia: Center for Research in Medical Education and Health Care; 2002.

19. Bendapudi NM, Berry LL, Frey KA, Parish JT, Rayburn WL. Patients' perspectives on ideal physician behaviors. Mayo Clin Proc. 2006;81:338-344.

20. Hojat M, Zuckerman M, Magee M, Mangione S, Nasca 
T, Vergare M, et al. Empathy in medical students as related to specialty interest, personality, and perceptions of mother and father. Personality and Individual Differences. 2005; 39:1205-15.

21. Nicolai J, Demmel R. The impact of gender stereotypes on the evaluation of general practitioners' communication skills: an experimental study using transcripts of physicianpatient encounters. Patient Educ Couns. 2007;69:200-5.

22. Rueckert L, Naybar N. Gender differences in empathy: the role of the right hemisphere. Brain and Cogn. 2008;67:162-7.

23. Salovey P, Sluyter D. Emotional development and emotional intelligence: educational implications. New York: Basic Books; 2001.

24. Eisenberg N, Strayer J. Empathy and its development. Cambridge: Cambridge University Press; 1990.

25. Hojat M, Fields S, Gonnella J. Empathy: an NP/MD comparison. Nurse Pract. 2003;28:45-7.

26. Crandall S, Marion G. Commentary: identifying attitudes towards empathy: an essential feature of professionalism. Acad Med. 2009;84:1174-6.

27. Yarascavitch C, Regehr G, Hodges B, Haas DA. Changes in dental student empathy during training. J Dent Educ. 2009;73:509-17.

28. Çınar N, Cevahir R, Şahin S, Sözeri C, Kuğuoğlu S. Evaluation of the empathic skills of nursing students with respect to the classes they are attending. Rev Eletr Enf. 2007; 9(3): Available from: http://www. fen.ufg.br/revista/v9/n3/v9n3a03.htm.

29. Bonvicini KA, Perlin MJ, Bylund CL, Carroll G, Rouse RA, Goldstein MG. Impact of communication training on physician expression of empathy in patient encounters. Patient Educ Couns. 2009;75:3-10.

30. Newton B, Barber L, Clardy J, Cleveland E, O'Sullivan P. Is there hardening of the heart during medical school? Acad Med; 2008;83:244-9.

31. Wilkes M, Milgrom E, Hoffman J. Towards more empathic medical students: a medical student hospitalization experience. Med Educ. 2002;36:528-533. 